\title{
DIE SUID-AFRIKAANSE JEUG IN VOORTREKKERTYDPERK
}

Mnr J.A. Visser*

The role of the South African Youth in the Voortrekker era is discussed in this article. Aspects such as education are brought into perspective with the peculiar circumstances of their lives during the Great Trek.

Weke vantevore is alles al deur die grensboere in gereedheid gebring om die Kaapkolonie te verlaat op soek na 'n nuwe vaderland. Die aand voor die Trek het die trekgoed soos jukke, skeie, stroppe en rieme uitgesprei voor die wa gelê. Hierdie wa was klein en smal met 'n tent van voor tot agter en sou 'n belangrike rol in die lewe van die Trekker speel. Dit was sy huis, sy hospitaal, sy binnekamer en sy vesting. Die Bybel as Gods woord het besondere betekenis gehad en was ook die vernaamste boek wat op die Trek meegeneem is. Nog boeke van belang was die Psalmboek, die Trap der Jeugd en Sluiter se liedere. Sy geweer was een van sy kosbaarste besittings want hiermee moes hy homself verdedig teen sy vyande en wilde diere. Alleen die allernoodsaaklikste is saamgeneem want ruimte was baie beperk. ${ }^{1}$

Mnr A.K. Bot beskryf die Trek as volg: "Stampend en stotend trek die waens oor die rowwe veld. Die geskreeu van die drywer en die blitsslag van sy lang sweep dwing die osse en hulle touleier: Noordwaarts! Weg van die Ou Kolonie met sy lief en sy leed, sy bekoring en sy teleurstellings. Dis vryheid wat die helde soek. Dis onafhanklikheidsdrang wat hierdie pioniers besiel. Dit is Godsvertroue wat hulle lei." 2

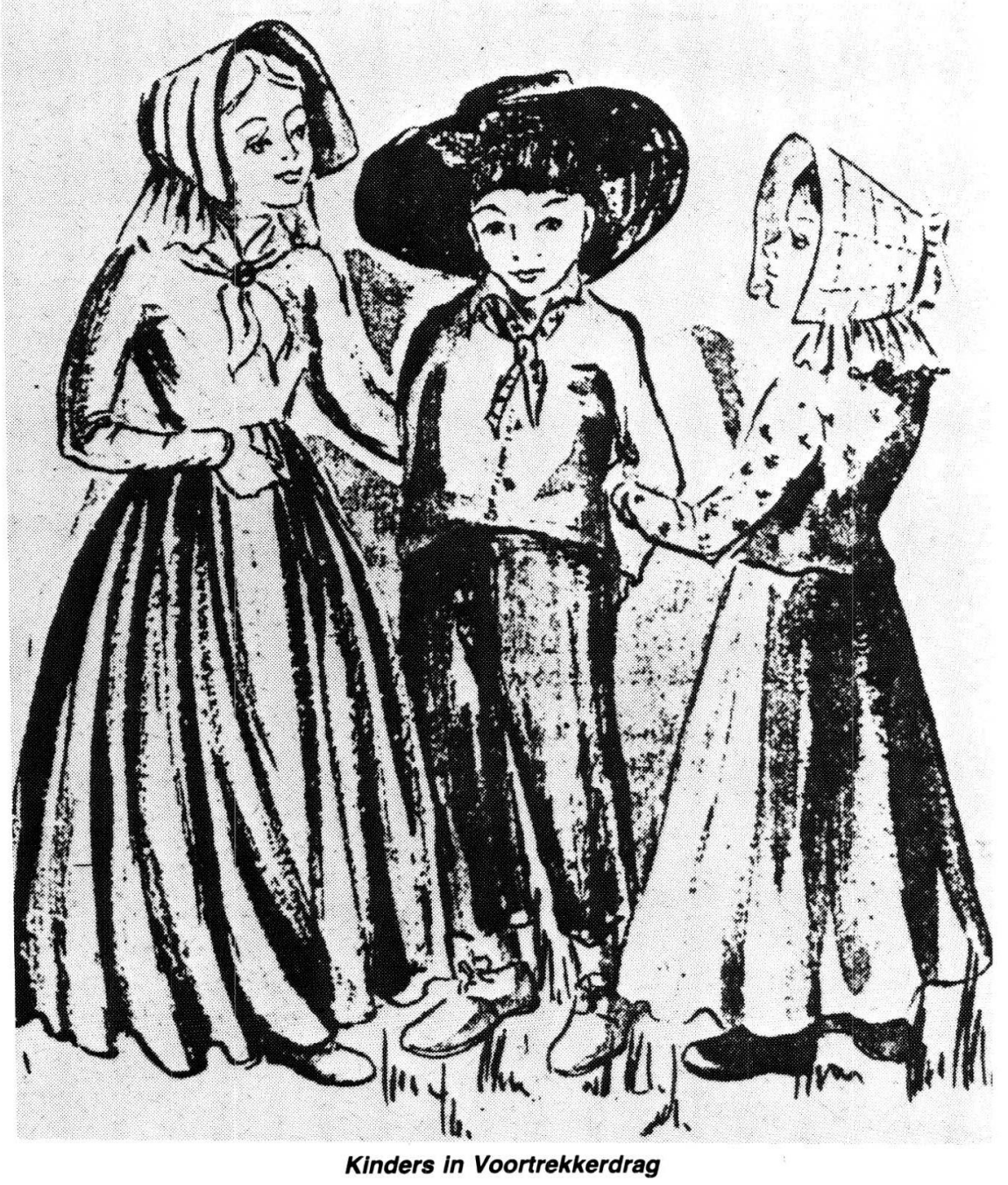


Vir die kinders was die Groot Trek 'n heerlike vooruitsig. Kinders het nie die erns van die Groot Trek besef nie en het enige verandering verwelkom met die vooruitsigte van maatjies met wie hulle heerlik kon speel. Vir die jonger kinders was dit ' $n$ groot avontuur en in hulle verbeelding het hulle die aantreklikste visioene geskilder. Die groter kinders, wat gehard was deur die gevare wat gedurig die grensboere bedreig het, sou 'n beter besef van die erns van die Groot Trek gehad het. $^{3}$

Die ouers, veral die moeders, het die kinders nie toegelaat om wild en ongeletterd groot te word nie, maar hulle is opgevoed om beskaafde en godvresende lede van die samelewing te word. Hulle is opgevoed met ' $n$ diepe besef van hulle plig teenoor hul ouers, hul kerk, hul land en volk. Hoe gevaarlik die omstandighede ook al was, die onderrig van die kinders is nooit verwaarloos nie. ${ }^{4}$

Die onderrig en opvoeding het ' $n$ essensiële deel van die ouerlike pligte gevorm. Elke kind moes lidmaat van die Kerk word en die Kerk het geen lidmaat aangeneem as hy of sy nie kon lees en skryf nie. Die lees kon nog gaan maar met die skrywe het dit moeilik gegaan want daar was 'n groot gebrek aan skryfbehoeftes, veral ink. Op die Groot Trek is daar allerlei middele aangewend om ink te maak en dan het die kinders leer skrywe. Dat hulle baie netjies kon skrywe, getuig geskrifte van daardie tyd wat in museums bewaar word. Die papier is al geel maar die netjiese skrif in ink het nog nie veel verbleik nie. $^{5}$

Aan moedersknie het die kinders geleer om te lees uit die Trap der Jeugd en die Bybel. Die Bybel was die vernaamste boek op die Trek en daaruit is daagliks, soggens vroeg en saans na die aandete deur die hoof van die gesin voorgelees. Van die kinders is verwag dat hulle moes onthou wat gelees is. Die huisgodsdiens was van groot belang want dit sou die Trekkers bewaar van verval. ${ }^{6}$ Dit was 'n plesier vir die kinders om ' $n$ versie uit die Bybel te leer en dan op Sondagoggend in die laer vir hul ouers op te sê. Op trek was daar gereeld elke Sondagoggend 'n erediens gehou wat deur almal bygewoon is. ${ }^{7}$

Enkele onderwysers het ook die Groot Tiek vergesel soos Daniël Pfeffer (Trichardt-trek), Tielman Roos (Potgieter-trek), Erasmus Smit (Maritztrek - hy het die leeraarsamp met die van die onderwysamp afgewissel), Wynand Marè
(Retief-trek) en nog ander van wie net die name bekend is. Alhoewel die onderwysers hulle deel op die gebied van die onderwys bygedra het, was die eintlike opvoeders van die geslag van die Voortrekkers die Afrikaanse Moeders. Hierdie rol het hulle tydens en na die Trek vervul. ${ }^{8}$

Alhoewel die onderwys gedurende die Groot Trek baie gebreke gehad het, word dit alles pragtig deur mnr. A.K. Bot saamgevat as volg: "Sonder 'n georganiseerde stelsel van onderwys, sonder hulpmiddele, sonder geboue of meubels het die Voortrekker sy kind bewaar vir verstandelike of sedelike degenerasie, het hy hom opgevoed in gehoorsaamheid, in eerbied vir gesag, in liefde vir volk en vaderland; kortom in die vrees van God. Dit was 'n opvoeding wat aangepas het by die omgewing en die lewensomstandighede en derhalwe voldoen het aan die eise van sy tyd. Dit het 'n geslag gekweek van onversaagde baanbrekers wat die nuwe vaderland maatskaplik, ekonomies en staatkundig sou ontgin, gerugsteun deur die sedelike krag van 'n stoer Calvinisme" 9

Heelwat kinders het aan die Groot Trek deelgeneem en hulle word vandag nog onthou vir heldedade wat hulle verrig het. In September 1837 het sowat tweeduisend Trekkers reeds die Oranjerivier oorgesteek. Die groter seuns moes omsien na die vee terwyl die groter dogters hulle moeders moes bystaan met die voorbereiding van voedsel en die versorging van kleiner boeties en sussies. Waar die kinders van 'n huisgesin net uit dogters bestaan het, moes die dogters behalwe hulle moeders ook hul vaders help met die versorging van vee. Waar omstandighede dit vereis het, moes seuns sowel as dogters soms gedurende die nag wagstaan om die laer teen vyandelike aanvalle te vrywaar en om vee teen wilde diere te beskerm. ${ }^{10}$

Die lewensgeskiedenis van die Voortrekkerkinders was eintlik baie tragies want hulle het nie alleen onder baie moeilike omstandighede opgegroei nie maar baie van hulle moes hulle lewens aflê in die stryd vir volk en vaderland. Verder was daar dikwels siekte onder die kinders. Dit is ook te begrype want hulle was gedurig aan allerlei weersomstandighede soos swaar reëns, hael en bitter koue blootgestel. Siektes soos masels, kinkhoes, waterpokkies en al die ander kindersiektes moes hulle op die waens en in tente deurmaak, soms sonder medisyne en altyd sonder ' $n$ mediese dokter. ${ }^{11}$ 
Die wa het ook gedien as kraaminrigting en baie babas het hier die eerste lewenslig aanskou. Alleen die sterkeres het oorleef terwyl die swakkeres gesterf het. Die Voortrekkerkinders het in 'n harde omgewing opgegroei, was fisies sterk en geestelik goed toegerus vir die aanslae van die lewe. ${ }^{12}$ Hulle het opgegroei in 'n lewe wat hulle gehard en gebrei het. Van kleinsaf moes hul saamhelp en verantwoordelike werk doen, hulle het daagliks wildediere bestry en reeds vroeg aan gevegte deelgeneem sodat hulle baie selfstandig ontwikkel het. ${ }^{13}$

Die seuns het reeds op ' $n$ vroeë ouderdom geleer om perd te ry en met die ou voorlaaier te skiet. Hulle het daagliks ure op die rûe van hulle perde deurgebring, gevare getrotseer en noue ontkomings beleef. In tye van gevaar wanneer die laer deur barbare aangeval is, het die groter seuns saam met hul vaders die voorste verdedigingslinie gevorm. Hulle het die krygskuns reeds op die Oosgrens in die Kaapkolonie aangeleer waar hulle hulself teen die Xhosas moes verdedig. Van kindsbeen af het hulle vertroud geraak met die hantering en gebruik van vuurwapens sodat hulle op ' $n$ betreklike jong ouderdom in uitstekende skuts ontwikkel het. Wanneer daar gevaar gedreig het moes die seuns sowel as die dogters help. Hulle het takke gekap en aange- sleep om die laer te versterk. Die seuns moes help skiet terwyl die dogters hul moeders moes bystaan om kooëls te giet en gewere te laai. ${ }^{14}$

Behalwe al die reeds genoemde verantwoordelikhede wat op die skouers van die seuns en dogters geplaas was, moes die seuns ook wild vir die pot skiet, vee in die veld oppas, toulei, verkenning doen en jag maak op gevaarlike wildediere wat die vee aangeval het. Die dogters daarenteen moes ook nog wasgoed was, klere maak, help met die voorbereiding van kos soos die bak van brood in ' $n$ uitgeholde miershoop, ensovoorts. ${ }^{15}$

Die eintlike swaarkry op die trekpad het begin toe die Voortrekkers in aanraking met die Matabeles en Zoeloes gekom het. Sommige van die trekkersgroepe soos die Van Rensburgs en die Liebenbergs is op wreedaardige wyse uitgemoor. ${ }^{16}$

In die slag van Vegkop in Oktober 1836 is die Voortrekkerlaer, wat bestaan het uit tussen dertig en veertig Voortrekkers, deur ongeveer sesduisend Matabeles aangeval. Die waens is in ' $n$ kring getrek om ' $n$ laer te vorm en binne in die laer is ' $n$ paar waens in die vorm van ' $n$ vierkant getrek. Hierdie waens in die vierkant is aan die

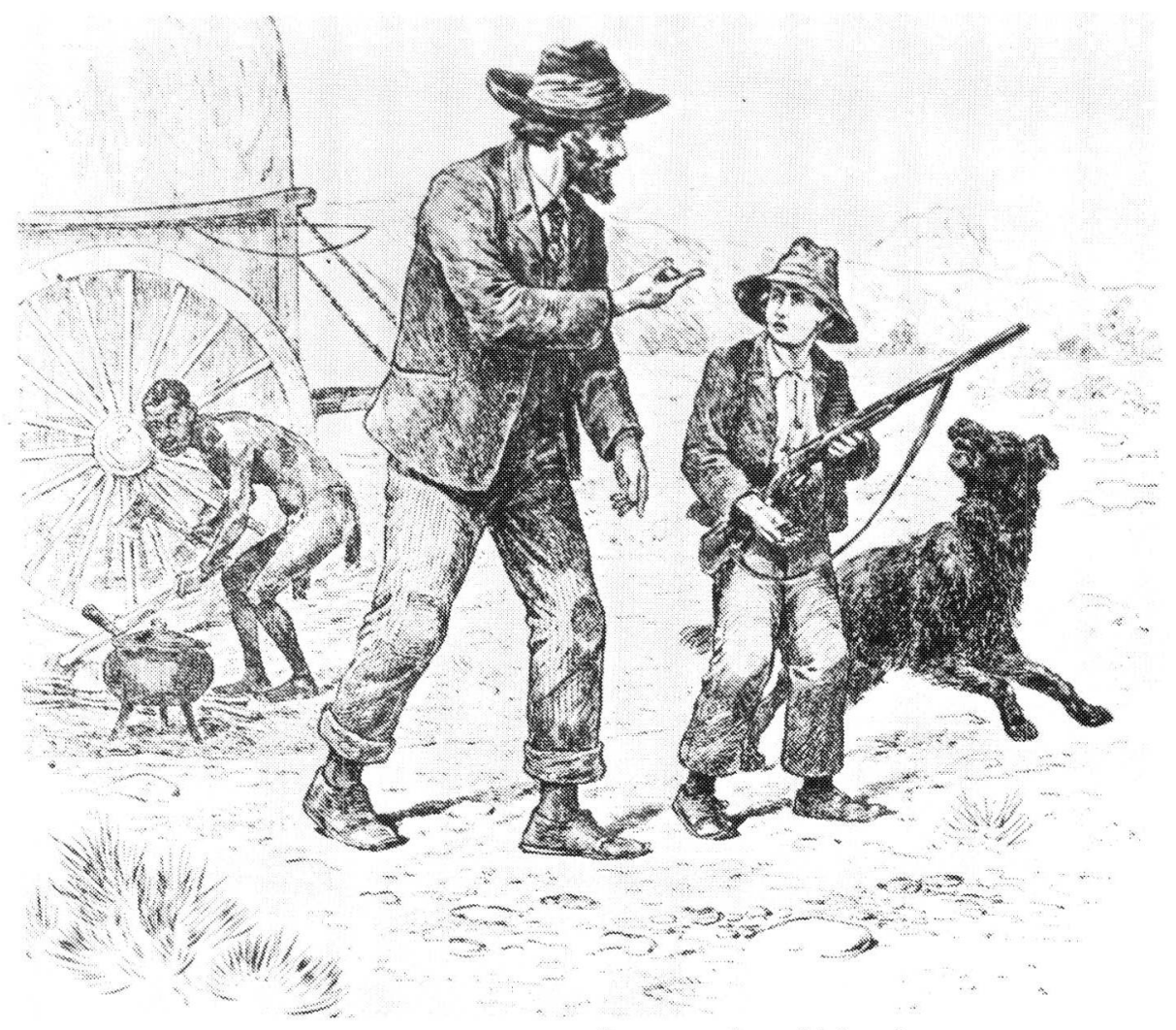

Voortrekkerseuns het vroeg leer skiet en jag 
kante en bo-op met planke en velle bedek om vir die ou moeders en klein kindertjies as skuiling te dien. Die planke en velle moes keer dat die assegaaie die mense tref. Voor die geveg het die vrouens en groter dogters koeëls gegiet. Tydens die geveg het die seuns gehelp skiet terwyl die vrouens en dogters die gewere vir die mans gelaai het. Van die dogters soos Nellie Botha (11 jaar oud) en haar sussie Fya (15 jaar oud) het nie net gewere gelaai nie maar net so hard soos die seuns en mans na die vyand geskiet. Paul Kruger wat destyds maar elf jaar oud was, het ook aan die slag van Vegkop deelgeneem. $\mathrm{Na}$ ' $\mathrm{n}$ verbete geveg wat drie tot vier uur geduur het, is die Matabeles verslaan en het hulle die wyk geneem. ${ }^{17}$

In die moord op Piet Retief is sy eie elfjarige seun Pieter, asook drie ander seuns, Dawie Liebenberg, Kootjie Opperman en Kosie Oosthuizen, saam met die manskappe om die lewe gebring. Daarna het Dingaan sy impies gestuur om die res van die Trekkers in Natal uit te moor. By Weenen, Blaauwkransrivier en Moordspruit is 41 mans, 56 vroue, 185 kinders en 250 gekleurde bediendes om die lewe gebring voordat die Zoeloemag gestuit is. ${ }^{18}$ Gedurende hierdie beproefde tydperk en net daarna is daar ongeëwenaarde dapperdade deur kinders verrig. Hier word veral gedink aan Voortrekkerkinders soos Petrus Bezuidenhout, Marthinus Oosthuizen, Dirkie Uys en nog baie ander.

Ten spyte van die gevare het die Voortrekkerkinders tog nog tyd gekry om te speel. Daar was geen winkels nie en hulle moes self hulle speletjies uitdink en hul speelgoedjies maak. In hul speletjies het hul hoofsaaklik die grootmenslewe om hul heen nageboots. Die seuns het waentjies gemaak en die dogtertjies het dit van wit tente voorsien. Klei-osse of dolosse is voor die waens ingespan. Die seuns het met kleilatte en slingers gespeel en soms het hulle ook met pyl en boog voëls geskiet. Die dogtertjies was nooit sonder 'n pop nie. Poppe kon op die Trek nie gekoop word nie en daarom is daar lappoppe gemaak waarvan daar vandag nog pragtige voorbeelde in ons museums te vinde is. ${ }^{19}$

Beskou mens die lappoppe van nader dan vind jy dat die hare van die poppe van lanfer gemaak is. Dit herinner ' $n$ mens aan die groot verlies wat die Voortrekkers gedurig gely het deur die dood van hul dierbares. Na die aanval van Dingaan was daar nie een gesin wat nie in rou verkeer het nie. Hoe treffend is die gediggie van Hilda
Postma oor "My Lappop" waarvan enkele versies hier aangehaal word.

"Oor verre hoë berge

het Leen ook saam getrek

Kyk bloed uit Kaffermoorde

Het hier haar rok gevlek.

Ja, die ou pop, sê Ouma

Het baie al deurleef

En om haar bont sis rokkie

Is 'rinnerings teer geweef." 20

Die wedervarings gedurende die Groot Trek het groot invloed uitgeoefen op die karakters van die seuns en dogters van daardie tyd. Niemand was miskien so beïnvloed as die seun, Paul Kruger, wat later die President van die Suid-Afrikaanse Republiek sou word nie. Toe sy ouers in 1835 die Kaapkolonie verlaat het, was hy maar 'n seun van 10 jaar oud. Saans, om die kampvuur het hy geluister na die grootmense wat vertel het waarom hulle die Kaapkolonie verlaat het. Toe hy ongeveer veertien jaar oud was, het hy in 'n sterk jong seun ontwikkel wat nie alleen fisies baie sterk was nie maar hy was ook ' $n$ goeie atleet en 'n uitstekende skut. Hy het hom as 'n knap skut bewys toe hy sy vader en vyf mans op ' $n$ leeujag vergesel het. Die jagters het hulle perde in Paul se sorg gelaat terwyl hulle met oorgehaalde gewere na die plek gestap het waar hulle vermoed het dat die leeu hom skuil hou. Daar is skertsend aan Paul gesê dat as die leeu op hom sou afstorm hy baie goed moet skiet. Meteens het die leeu op die perde afgestorm, Paul het aangelê en hom 'n doodskoot toegedien. Die persoon wat op spottender wyse aan hom gesê het om goed te skiet het voor die leeu gaan sit om die ou maanhaar se tande, wat besonder groot was, te meet. Sonder enige bedoelings het Paul die leeu 'n skop teen die maag gegee, waarop die dooie leeu meteens ' $n$ vreeslike brul gegee het, sodat die persoon die tandemetery skoon vergeet en van skrik op sy rug geval het. Die ander jagters het geskater van die lag, want elke jagter weet dat 'n dooie leeu, as 'n mens kort na sy dood op sy maag trap, 'n laaste brulgeluid uitstoot asof hy nog leef. Die persoon wat van skrik op sy rug geval het, wou Paul 'n pak slae gee maar gelukkig het die ander lede van die jaggeselskap tussenbeide getree en dit verhoed. ${ }^{21}$

Grappige voorvalle, soos hierbo vermeld, het die tragiese en swaarkry van die Voortrekkerkinders effens vervrolik. Hulle was egter gedurig aan gevare blootgestel sodat hulle maar baie 
min die ware kindervreugde van 'n sorgelose jeug kon geniet. Baie kinders het hulle jong lewens opgeoffer as kindermartelare ter wille van 'n vrye en onafhanklike volk en vaderland. Daarom is die Afrikanervolk dit aan die Voortrekkerkinders verskuldig om hul nagedagtenis in ere te hou en op eervolle wyse melding te maak van hul heldhaftige aandeel aan die Groot Trek. Die digter Jan F.E. Cilliers stel dit so pragtig in sy gedig "Dingaansdag" waarvan net die laaste versie aangehaal word:

\section{"Afrika!}

Afrika!

Eer hul gedagtenis

En as jou vryheidsdag

eens oor jou velde lag,

weet wie te danke is -

eer hul gedagtenis."22

- Mnr J.A. Visser, MA, TOD, is verbond aan die Militêre Informasieburo van die SAW.

\section{Verwysings}

1. Boëseken A.J., Krüger, D.W., Kieser, A., Drie Eeue Die verhaal van Ons Vaderland, Deel 2, Nasionale Boekhandel, Kaapstad, 1952, pp $177-178$.

2. Bot, A.K., Honderd Jaar Onderwys in Transvaal 1836-1936, Staatsdrukker, Pretoria, 1936, p 157.

3. Postma, R., "Die Kind in die Groot Trek," Gedenkuitgawe Die Huisgenoot, Desember 1938, p 157.

4. Ibid., p 156.

5. Ibid.

6. Boëseken, A.J., Krüger, D.W., Kieser, A., Drie Eeue, p 178.

7. Postma, R., "Die Kind in die Groot Trek", p 156.

8. Bosman, I.D., "Onderwys en die Groot Trek", Gedenkuitgawe Die Huisgenoot, Desember 1938, p 159

9. Bot. A.K., Honderd Jaar Onderwys in Transvaal 1836-1936, p 11.

10. Child, D., Yesterday's Children, Howard Timmins, Kaapstad, 1969, pp $100-101$.

11. Postma, R. "Die Kind en die Groot Trek", p 156

12. Child, D., Yesterday's Children, p 102.

13. Lugtenburg, A.H., Geskiedenis van die Onderwys in die SA Republiek 1836-1900, J.L. van Schaik Pretoria, 1925, p 20.

14. Postma, R. "Die Kind en die Groot Trek", p 157.

15. Child, D., Yesterday's Children, p 102

16. Ibid.

17. Kotzé, D.J., Dapper Kinders van Suid-Afrika, Die Sondagskool Boekhandel, Bloemfontein, s.j., pp 48-49.

18. Boëseken, A.J., Krüger, D.W., Kieser A., Drie Eeue, p 218.

19. Postma. R. "Die Kind en die Groot Trek", pp 156-157.

20. Ibid., p 157.

21. Kotzé, D.J., Dapper Kinders van Suid-Afrika, pp 60-61

22. Postma, R. "Die Kind en die Groot Trek", pp 156-157. 